Communications in Physics, Vol. 24, No.3S1 (2014), pp. 51-56

DOI:10.15625/0868-3166/24/3S1/5145

\title{
PREPARATION OF POSITIVELY CHARGED MEMBRANE FROM NATURAL RUBBER LATEX BLENDING WITH CHITOSAN
}

\author{
WIRACH TAWEEPREDA AND SUPAWADEE TUAYBUT \\ Department of Materials Science and Technology, Faculty of Science, \\ Prince of Songkla University, Hat-Yai, Songkhla 90110, Thailand \\ SINEENART PUANGMANEE \\ Faculty of Environmental Management, \\ Prince of Songkla University, Hat-Yai, Songkhla 90110, Thailand \\ TRAN DANG KHOA \\ Department of Bionanotechnology, Faculty of Physic engineering and Nanotechnology, \\ University of Engineering and Technology, Vietnam National University, Hanoi \\ E-mail: wirach.t@psu.ac.th \\ Received 04 June 2014 \\ Accepted for publication 24 August 2014
}

\begin{abstract}
Film formation of natural rubber latex (NRL) blending with various concentrations of chitosan were investigated. Atomic force microscopy (AFM) images clearly showed that the NRL film covered chitosan phase. Roughness of the film which was calculated from AFM image was increased with increasing chitosan concentration. Miscibility of NRL and chitosan in solution was investigated by using dynamic mechanical thermal analysis (DMTA) and found that chitosan incorporated with NRL less than 40 weight percentage (wt\%) was partially miscible. Films of the chitosan blending with higher NRL contents exhibited two peaks of glass transition temperatures. Interfacial polarization and dielectric properties of polymer films were improved with increasing NRL contents. Chemical structure of the blends were characterized by using attenuated total reflectance Fourier transform infrared spectroscopy (ATR-FTIR).
\end{abstract}

Keywords: natural rubber, chitosan, magnetic, dielectric, AFM..

\section{INTRODUCTION}

Chitosan from sea shell is a well-known membrane material for water-alcohol pervaporation [1,2], carbon dioxide selective [3], direct methanol fuel cell [4], protein separation and concentration [5], moreover, chitosan acts as a chelating agent for heavy metal removal [6] due to its positive charge present in the polymeric chain such as amino group. However, chitosan has a high molecular weight and low solubility in most solvents, which causes practical problems in its applications. A number of publications deal with incorporation of chitosan with natural rubber (NR) to obtain higher permeability [7,8] and selectivity as well as good thermal stability $[9,10]$. Incorporation of chitosan with NR has been done via solution blend (homogeneous reaction) and 
dry blend (heterogeneous reaction). Solution blend of chitosan with NR showed that the both of permeation flux and separation selectivity of water-isopropanol mixtures were increased with increasing chitosan content. Previous work from the same laboratory explored a very interesting route to degraded and modified chitosan functional groups, mostly composed by amino groups, using argon plasmas and glutaraldehyde, respectively [11]. The use of a bifunctional agent can block amino groups and turn chitosan structures more inert and resistant to acidic media.

In this study, the polymeric films were prepared from incorporation of chitosan solution with NR latex. The films were characterized and analyzed by atomic force microscope, dynamic mechanical thermal properties, Fourier transform infrared spectra and dielectric properties. To the best of our knowledge, this is the first time to report the film formation and properties of positively charged membrane from NR latex blending with chitosan solution.

\section{EXPERIMENTS}

High ammonia concentrated NR latex (NRL) with dry rubber content (DRC) $60.1 \%$ by weight was purchased from Chalong Latex Industry, Songkla, Thailand. Chitosan (deacetylation degree of $85 \%$ with average molecular weight is $500,000 \mathrm{~g} / \mathrm{mol}$ ) was purchased from Seafresh Industry Public Co., Ltd. 3 grams Chitosan was dissolved in 97 grams acetic acid solution (10\% $\mathrm{v} / \mathrm{v}$ ) by stirring for 48 hours and filtering to remove undissolved matter. The chitosan solution was directly mixed with NRL (DRC $=40 \%$ by weight in the presence with stabilizer $0.5 \%$ by weight) by varying weight ratio between chitosan solution and NRL.

The mixture was poured into petri dish and followed by drying at room temperature. The polymer films were neutralized by immersing in $4 \%$ (w/v) $\mathrm{NaOH}$ solution and washing with water until the washing water $\mathrm{pH}$ reached closed to 7.0. The resulting polymer films were left to dry at room temperature in a dust free chamber.

\section{Characterizations}

Surface morphology of membrane was studied using atomic force microscope (AFM), Park System XE70. The surface roughness average $\left(R_{a}\right)$ and root mean squared $\left(R_{q}\right)$ were calculated from Nanoscope software by using the following equation:

$$
\begin{aligned}
& R_{a}=\frac{1}{n} \sum_{j=1}^{n}\left|Z_{j}\right| \\
& R_{q}=\sqrt{\frac{1}{n} \sum_{j=1}^{n} Z_{i}^{2}}
\end{aligned}
$$

where $Z_{j}$ is the difference between the height and the mean plane current, and $n$ is number of points.

The dynamic mechanical properties of the obtained membrane were analyzed using Dynamic Mechanical Thermal Analyser (DMTA; Model-V, supplied by Rheometric Scientific). The shape of test sample was rectangular, $25 \mathrm{~mm}$ long, $10 \mathrm{~mm}$ wide and $1.5 \mathrm{~mm}$ thick. The single cantilever mode of deformation was used under the test temperature range from $-100^{\circ} \mathrm{C}$ to $50^{\circ} \mathrm{C}$ with a heating rate of $3^{\circ} \mathrm{C} / \mathrm{min}$; ; the test frequency being $1 \mathrm{~Hz}$. The cooling process was achieved through liquid nitrogen. 
Dielectric measurements were carried out in the frequency range $75 \mathrm{kHz}$ up to $30 \mathrm{MHz}$ by using Precision LCR meter (Agilent 4285A).

\section{RESULTS AND DISCUSSION}
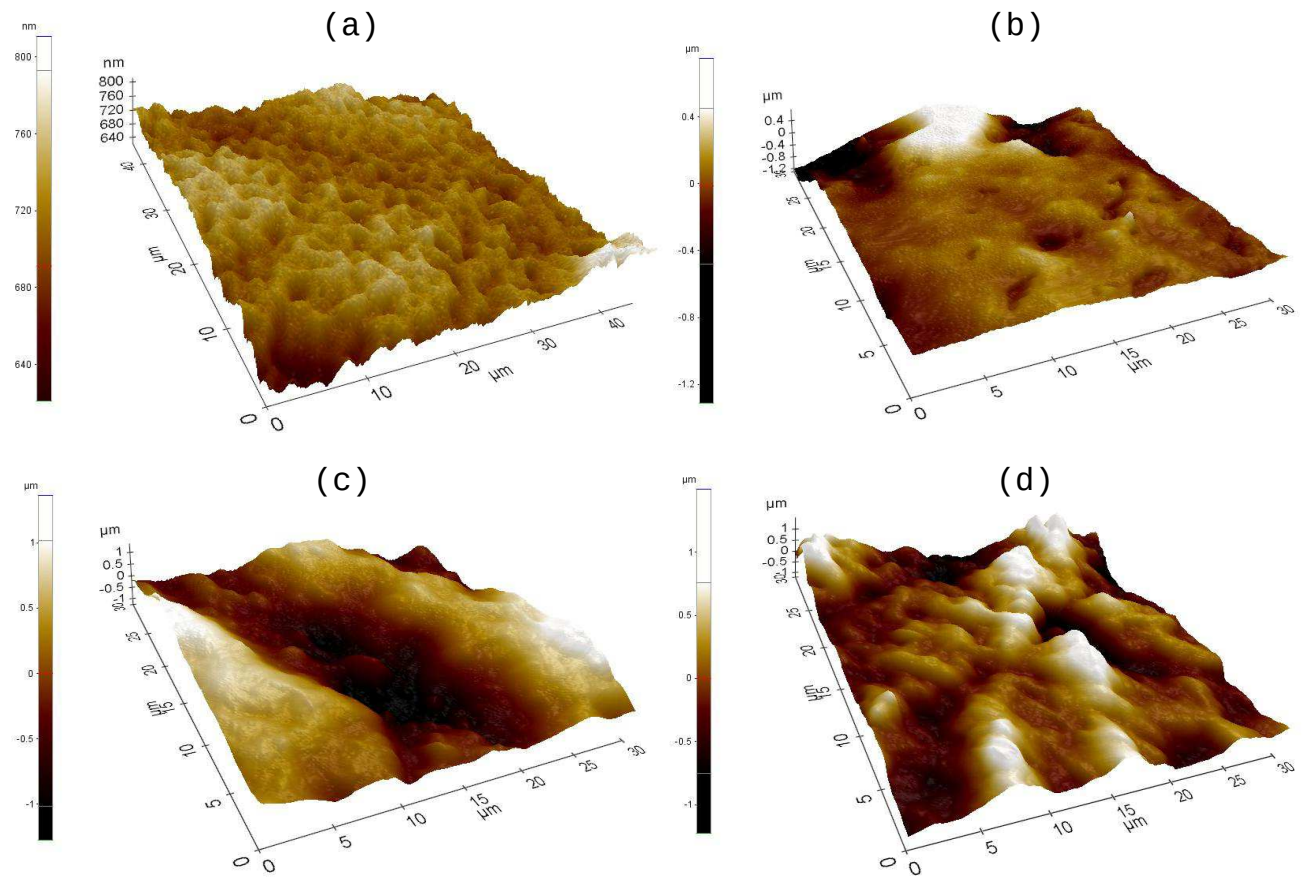

Fig. 1. The AFM images of films from chitosan (a) and NR blending with chitosan at weight ratio NR-CS30 (b), NR-CS20 (c), and NR-CS10 (d).

The AFM images in Fig. 1 clearly showed that the chitosan incorporated with NR formed the aggregate structure with high surface roughness. The peak-to-valley $\left(R_{p v}\right)$, surface roughness average $\left(R_{a}\right)$, and root mean squared $\left(R_{q}\right)$ were calculated and presented in Table 1.

Table 1. Surface roughness values of membrane on mica substrate

\begin{tabular}{|c||c|c|c|c|c|c|}
\hline Membrane & Min (nm) & Max (nm) & Mean (nm) & $\mathbf{R}_{p v}(\mathbf{n m})$ & $\mathbf{R}_{q}(\mathbf{n m})$ & $\mathbf{R}_{a}(\mathbf{n m})$ \\
\hline \hline Chitosan & 708.6 & 721.2 & 713.9 & 12.6 & 3.8 & 3.2 \\
\hline NR-CS10 & -1226 & 1499 & 0 & 2725 & 386 & 299 \\
\hline NR-CS20 & -554 & 573 & 0 & 1128 & 330 & 295 \\
\hline NR-CS30 & -149 & 163 & 6 & 312 & 91 & 80 \\
\hline
\end{tabular}

The images show the sine structure of chitosan surface transformed to larger microfibril bundles after incorporated with NR. These suggest that the polarity of chitosan membrane is decreased, showing the potential to produce the chitosan with higher strength and stiffness. 
The properties obtained from the dynamic mechanical thermal analysis are the storage modulus (E'), loss modulus (E'), and loss tangent $(\tan \delta)$ of the biopolymeric blending film is recorded as a function of temperature from -100 to $50^{\circ} \mathrm{C}$ and showed in Fig. 2. Fig. 2, the storage modulus is found to increase with incorporation chitosan with higher NR content. The incorporation of NR has improved the stiffness of the chitosan around the glassy region. The damping property $(\tan \delta)$ which is the ratio of the dynamic loss modulus to the dynamic storage modulus is found to increase with incorporation chitosan with NR. Since chitosan is rigid with it dissipates energy and thus the height of damping peak increases. The $\tan \delta$ peaks observed correspond to the glass transition temperature $\left(T_{g}\right)$ of the matrix. The $T_{g}$ of the obtained bio-blend is increased indicates good interaction between NR and chitosan.

More details of polymer functional groups were studied using ATR-FTIR analysis. Fig. 3 shows the major characteristic peaks of NR. These are at $3025 \mathrm{~cm}^{-1}(=\mathrm{CH}$ stretch), $2956 \mathrm{~cm}^{-1}$ (C-H stretch of methyl group), $2915 \mathrm{~cm}^{-1}$ (C$\mathrm{H}$ stretch of methylene group), 1375 $\mathrm{cm}^{-1}$ (C-H stretch of methyl group), $1453 \mathrm{~cm}^{-1}$ (C-H stretch of methylene group), and at $835 \mathrm{~cm}^{-1}(\mathrm{C}-\mathrm{H}$ wagging). The spectrum of chitosan membranes as shown in Fig. 3 had no obvious difference between each of membrane. However, when a detail observation was made, C-O-C groups were affected. For the incorporation of chitosan with NR, the peak at $1040 \mathrm{~cm}^{-1}$ (C-O-C out-of-plane bend) increased remarkably.

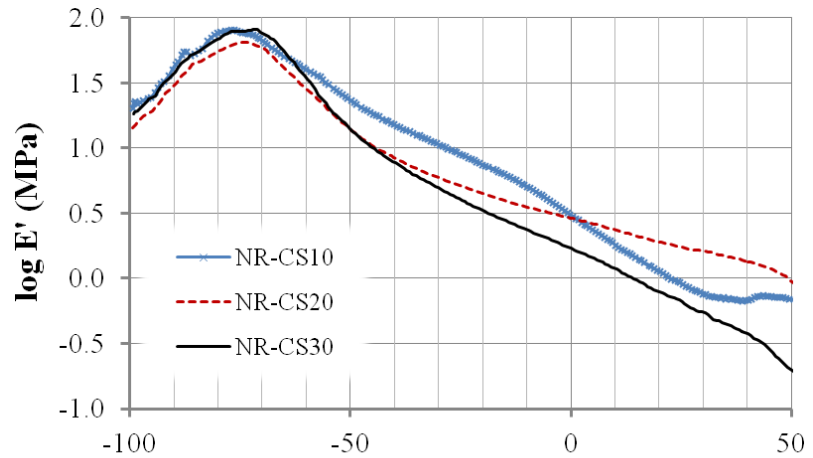

(a)

Temperature $\left({ }^{\circ} \mathrm{C}\right)$

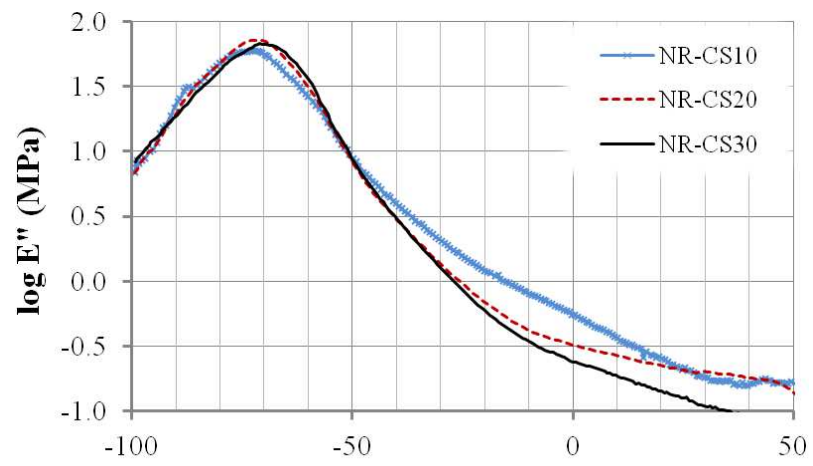

(b)

Temperature $\left({ }^{\circ} \mathrm{C}\right)$

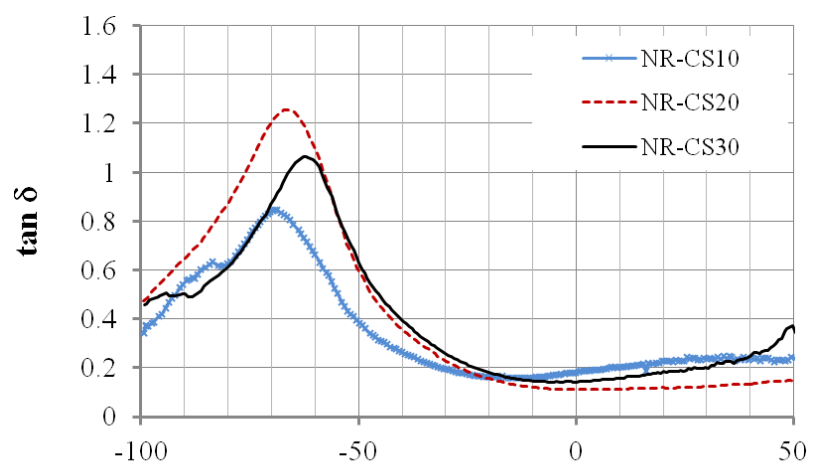

(c)

Temperature $\left({ }^{\circ} \mathrm{C}\right)$

Fig. 2. Dynamic mechanical thermal properties of chitosan incorporated with NR with difference compositions: (a) storage modulus, (b) loss modulus, and (c) $\tan \delta$ at temperature from $-100^{\circ} \mathrm{C}$ to $50^{\circ} \mathrm{C}$. 


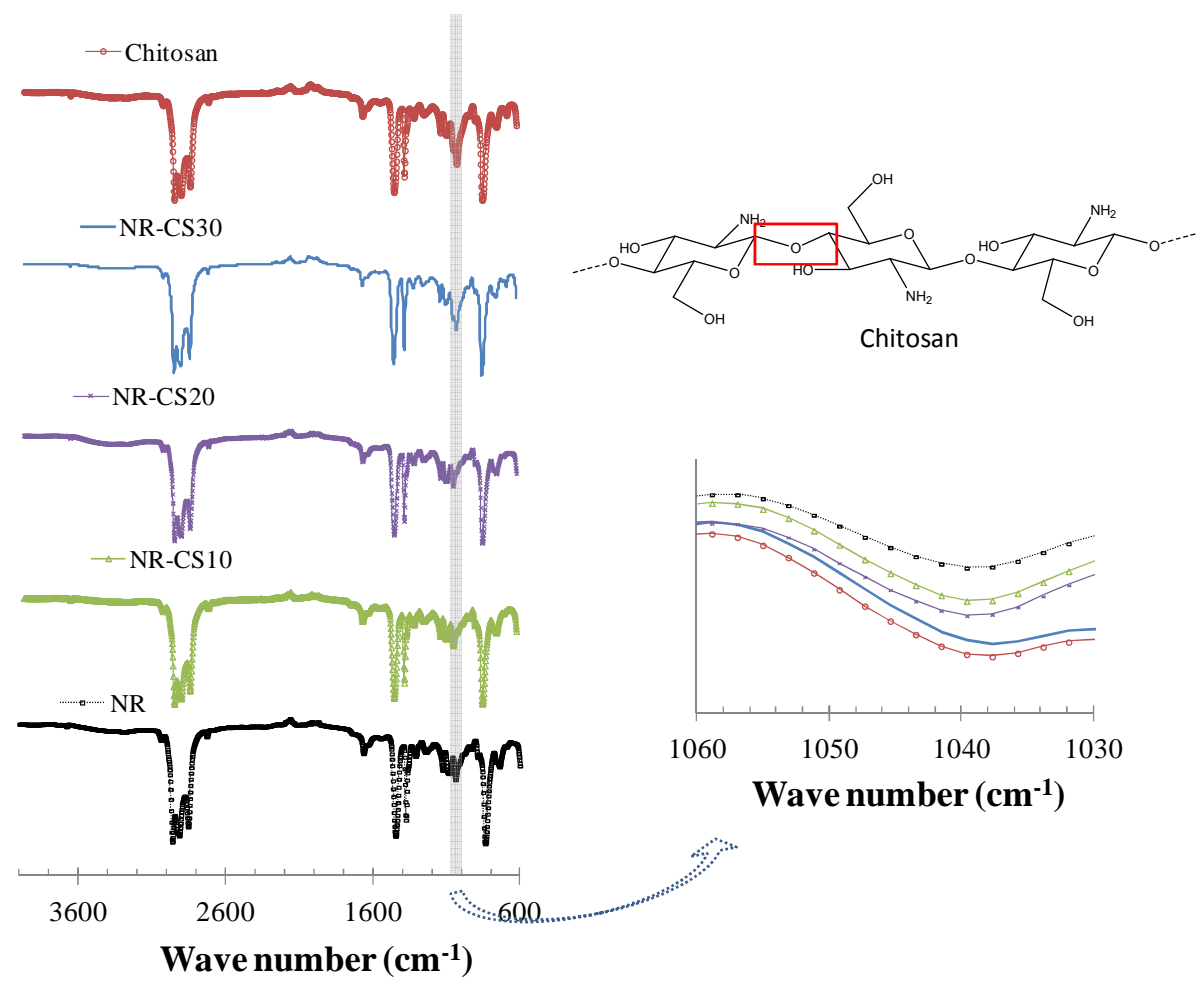

Fig. 3. The IR absorption spectra of NR and NR blending with chitosan.

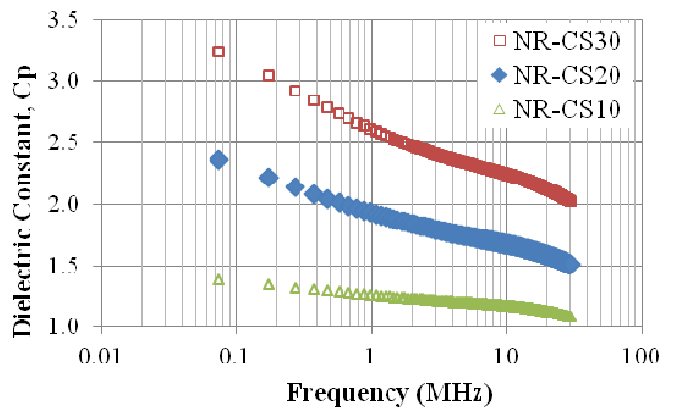

(a)

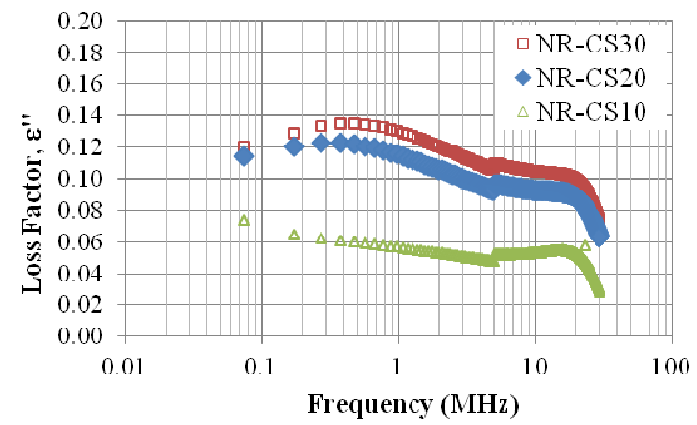

(b)

Fig. 4. Dielectric properties of chitosan incorporated with NR with difference compositions: (a) dielectric constant and (b) loss factor at various frequency.

The permittivity and dielectric loss of polymer films were measured over the frequency range from $75 \mathrm{kHz}$ up to $30 \mathrm{MHz}$ at room temperature. Dielectric constant of the polymer film with higher content of chitosan was increased as shown in Fig. 4. Blending of chitosan with NR, the dense NR film covered with chitosan particles results was formed and shown that the film conductivity decreased. 


\section{CONCLUSION}

The membrane obtained from the incorporation of chitosan with NR showed that the mechanical property is improved. The dielectric constant revealed with interfacial polarization and conductivity of polymer film is mainly changed with NR content. NR film was formed and covered chitosan particle decreased its dielectric properties.

\section{ACKNOWLEDGEMENTS}

The authors would like to thank Prince of Songkla University as the research grant. S.P would like to thank the Commission on Higher Education (CHE) for supporting her Ph.D. studentship.

\section{REFERENCES}

[1] D. Anjali Devi, B. Smitha, S. Sridhar, T.M. Aminabhavi, J. Membr. Sci. 262 (2005) 91-99.

[2] Young Moo Lee, Sang Yong Nam, Dong Jin Woo, J. Membr. Sci. 133 (1997) 103-110.

[3] Louei A. El-Azzami, Eric A. Grulke, J. Membr. Sci. 328 (2009) 15-22.

[4] Yan Xiang, Meng Yang, Zhibin Guo, and Zheng Cui, J. Membr. Sci. 337 (2009) 318-323.

[5] R. S. Vieira and M. M. Beppu, Water Res. 40 (2006) 1726-1734.

[6] S. Roller, N. Covill, International Journal of Food Microbiology 47 (1999) 66-77.

[7] S. M. Sapuan, F. Mustapha, D. L. Majid, Z. Leman, A. H. M. Ariff, M. K. A. Ariffin, M. Y. M. Zuhri, M. R. Ishak, and J. Sahari, Key Engineering Materials $471-472$ (2011) 851.

[8] H. Ismail, S.M. Shaari, and N. Othman, Polymer Testing 30(7) (2011) 784-790.

[9] A. A. Kittur, S. S. Kulkarni, M. I. Aralaguppi, M. Y. Kariduraganavar, Journal of Membrane Science 247 (2005) 75-86.

[10] G. Clarizia, C. Algieri, and E. Drioli, Polymer 45 (2004) 5671-5681.

[11] P. Wanichapichart, R. Sungkum, W. Taweepreeda, and M. Nisoa, Surf. Coat. Technol. 203(17-18) (2009) 25312535. 